\title{
Global Cylinder Identification and Monitoring System: Nonproliferation Concerns and Baseline Definition
}

May 2013

Prepared by Jessica White-Horton Michael Whitaker James Morgan Sean Branney

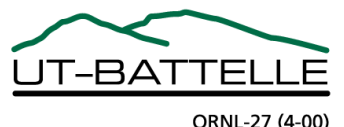




\title{
DOCUMENT AVAILABILITY
}

Reports produced after January 1, 1996, are generally available free via the U.S. Department of Energy (DOE) Information Bridge.

Web site http://www.osti.gov/bridge

Reports produced before January 1, 1996, may be purchased by members of the public from the following source.

\author{
National Technical Information Service \\ 5285 Port Royal Road \\ Springfield, VA 22161 \\ Telephone 703-605-6000 (1-800-553-6847) \\ TDD 703-487-4639 \\ Fax 703-605-6900 \\ E-mail info@ntis.gov \\ Web site http://www.ntis.gov/support/ordernowabout.htm
}

Reports are available to DOE employees, DOE contractors, Energy Technology Data Exchange (ETDE) representatives, and International Nuclear Information System (INIS) representatives from the following source.

Office of Scientific and Technical Information

P.O. Box 62

Oak Ridge, TN 37831

Telephone 865-576-8401

Fax 865-576-5728

E-mail reports@osti.gov

Web site http://www.osti.gov/contact.html

This report was prepared as an account of work sponsored by an agency of the United States Government. Neither the United States Government nor any agency thereof, nor any of their employees, makes any warranty, express or implied, or assumes any legal liability or responsibility for the accuracy, completeness, or usefulness of any information, apparatus, product, or process disclosed, or represents that its use would not infringe privately owned rights. Reference herein to any specific commercial product, process, or service by trade name, trademark, manufacturer, or otherwise, does not necessarily constitute or imply its endorsement, recommendation, or favoring by the United States Government or any agency thereof. The views and opinions of authors expressed herein do not necessarily state or reflect those of the United States Government or any agency thereof. 


\title{
GLOBAL CYLINDER IDENTIFICATION AND MONITORING SYSTEM: NONPROLIFERATION CONCERNS AND BASELINE DEFINITION
}

\author{
Jessica White-Horton \\ J. Michael Whitaker \\ James Morgan $\dagger$ \\ Sean Branney* \\ $\dagger$ InSolves Associates \\ *Savannah River National Laboratory
}

Date Published: May 2013

Prepared by

OAK RIDGE NATIONAL LABORATORY

Oak Ridge, Tennessee 37831-6254

Managed by

UT-BATTELLE, LLC

for the

U.S. DEPARTMENT OF ENERGY

under contract DE-AC05-00OR22725 



\section{CONTENTS}

\section{Page}

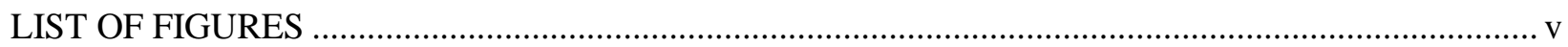

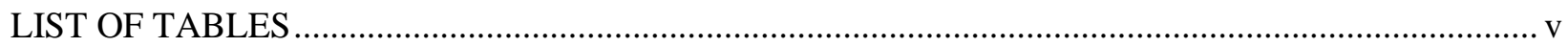

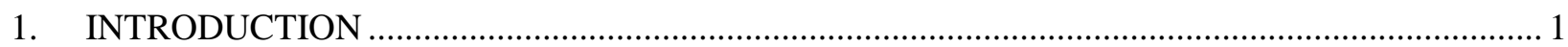

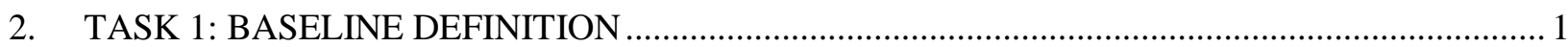

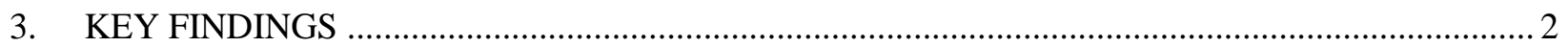

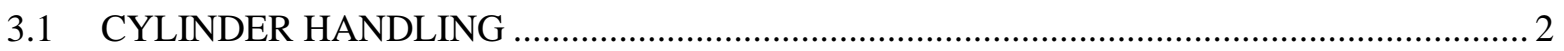

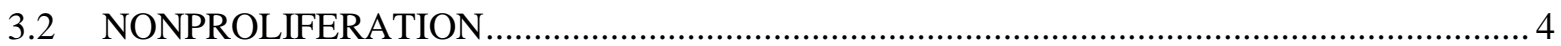

4. SUMMARY AND RECOMMENDATIONS FOR A CYLINDER IDENTIFICATION

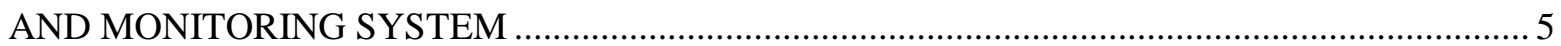

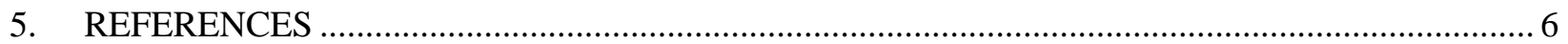





\section{LIST OF FIGURES}

Fig. 1. Movement of 48Y and 30B cylinders within the nuclear fuel cycle. ........................................ 3

\section{LIST OF TABLES}

Table 1. Diversion and undeclared production pathways ................................................................. 4 


\section{Acknowledgement}

This work was sponsored by the U.S. Department of Energy/National Nuclear Security Administration through the Next Generation Safeguards Initiative. The paper reflects the work of a multi-laboratory team and their subcontractors. The authors are pleased to acknowledge the contributions to this project by Ed Wonder (QinetiQ North America), Brian Boyer and Carolynn Scherer (LANL), Michael Curtis and Travis Gitau (PNNL), and Dan Collier (NAC International). 



\section{INTRODUCTION}

With growing nuclear commerce and new safeguards initiatives, the international safeguards system continues to face ever-increasing demands to verify nuclear materials. Emerging proliferation threats from both state and non-state actors are also leading to increased concerns over the diversion of nuclear materials - for example, the loss of cylinders containing uranium hexafluoride $\left(\mathrm{UF}_{6}\right)$ during transport or the introduction of undeclared feed into enrichment plants. The International Atomic Energy Agency (IAEA) goal for detecting the diversion of a significant quantity (SQ) of natural or low-enriched uranium (LEU) is 1 year. If a proliferant state were able to obtain a cylinder containing natural or low-enriched $\mathrm{UF}_{6}$, it could produce a SQ of highly enriched uranium (HEU) (25 kilograms) in less than a year using a moderately sized enrichment facility.

To address this nonproliferation concern, the National Nuclear Security Administration initiated a 5 year program in 2011 to demonstrate, at the proof-of-concept level, a UF 6 cylinder identification and monitoring system. ${ }^{1}$ The concept developed under this program could provide an integrated solution to meet both industry needs for uniquely identifying cylinders to improve cylinder operations and challenges facing international safeguards for detecting the diversion of LEU and undeclared production. The program has six principal tasks: (1) define the problem, (2) establish requirements for a unique identifier (UID) and cylinder monitoring system and develop a concept of operations, (3) determine cylinder monitoring devices and technology, (4) develop a registry database to support proof-of-concept demonstration, (5) integrate a prototype for a demonstration, and (6) demonstrate proof of concept.

This report summarizes the key findings of the initial task to define the problem and provides information for the second task to develop requirements and a concept of operations for a cylinder identification and monitoring system.

\section{TASK 1: BASELINE DEFINITION}

The baseline definition task describes the nonproliferation concerns and provides a basis for a cylinder identification and monitoring concept by documenting the life cycle of a cylinder, identifying diversion and undeclared production pathways, assessing the capability of current international safeguards methods to detect these pathways, reviewing national and international cylinder standards, and engaging key stakeholders. Task 1 was accomplished by a multi-laboratory team comprised of subject matter experts from Los Alamos National Laboratory, Oak Ridge National Laboratory, Pacific Northwest National Laboratory, Savannah River National Laboratory, and subcontractors. The team produced four technical reports:

- The Life Cycle of $30 B$ and $48 Y$ Cylinders, ${ }^{2}$

- Identifying UF $F_{6}$ Cylinder Diversion and Undeclared Production Pathways, ${ }^{3}$

- Methods of Detecting Diversion and Undeclared Use of UF ${ }_{6}$ Cylinders, ${ }^{4}$ and

- Developing an International Standard for Identifying $U F_{6}$ Cylinders. ${ }^{5}$

The initial report on the cylinder life cycle documents cylinder manufacturing, handling, and operation practices; transportation and storage practices; and cylinder retirement/disposal practices. The content is based principally on activities related to US regulations, operating facilities, and experiences, but also identifies applicable international standards. The report provides the technical basis for the evaluations conducted in the subsequent diversion and detection reports. 
The diversion and undeclared production pathways report identifies nine scenarios in which a state (that has an IAEA safeguards agreement in place) could circumvent its safeguards obligations and produce HEU. Using cylinder flow diagrams described in the life cycle report, the team analyzed the scenarios required to produce an SQ of HEU from a $48 \mathrm{Y}$ or $30 \mathrm{~B}$ cylinder and identified potential indicators and concealment activities.

The methods of detecting report presents current IAEA safeguarding practices for detecting the diversion and undeclared production pathways and identifies potential weaknesses in the current practices.

The international standard report describes the current American National Standards Institute and International Organization for Standardization standards and which ones may require revisions to accommodate a UID. The team reviewed the current standards and subsequently identified possible changes to the current nameplate (or elsewhere on the cylinder's surface) that would not cause damage to the cylinder and at the same time could improve the IAEA's ability to account for each cylinder.

In preparing these technical reports, conversations with major stakeholders (industry, state systems of accounting for and control of nuclear material, and the IAEA) played an important role in helping the team understand the problems facing current cylinder identification and monitoring practices, as well as the operational practices of the fuel cycle facilities involved in this study. The team had numerous contacts with industry to ensure that facility operational cylinder practices were documented correctly. Other discussions with industry allowed the team to determine the potential uses and advantages for having a standardized approach for identifying and monitoring cylinders, and allowed industry to provide input into the development of a cylinder monitoring system that optimally addresses safeguards needs and operational practices.

\section{KEY FINDINGS}

The key findings from Task 1 can be grouped into two major topics:

- cylinder handling and

- nonproliferation.

\subsection{CYLINDER HANDLING}

The $\mathrm{UF}_{6}$ cylinder life cycle report identifies industry practices that are relevant for future cylinder identification and monitoring systems. Typically, model $48 \mathrm{Y}$ cylinders are used for natural uranium and model $30 \mathrm{~B}$ cylinders are used for uranium enriched up to $5 \%{ }^{235} \mathrm{U}$. Figure 1 illustrates the flow of these cylinders throughout the front end of the nuclear fuel cycle. ${ }^{2}$ The number of cylinders transported globally between facilities is estimated to be less than 20,000 per year $(\sim 9,000$ model $48 \mathrm{Y}$ cylinders of natural uranium and $\sim 7,000$ model 30B cylinders of LEU). Additionally, $\sim 8,000$ model $48 \mathrm{Y}$ cylinders are filled with depleted tails material and placed in long-term, on-site storage each year. ${ }^{6}$ During the course of their life cycle, the cylinders may be subject to temperatures ranging from $-40^{\circ} \mathrm{F}\left(-40^{\circ} \mathrm{C}\right)$ to $+235^{\circ} \mathrm{F}\left(+113^{\circ} \mathrm{C}\right)$, with the higher temperature condition being in either a steam or dry air heat environment. The cylinders may also be exposed to hydrogen fluoride gas in steam-heated autoclaves. 


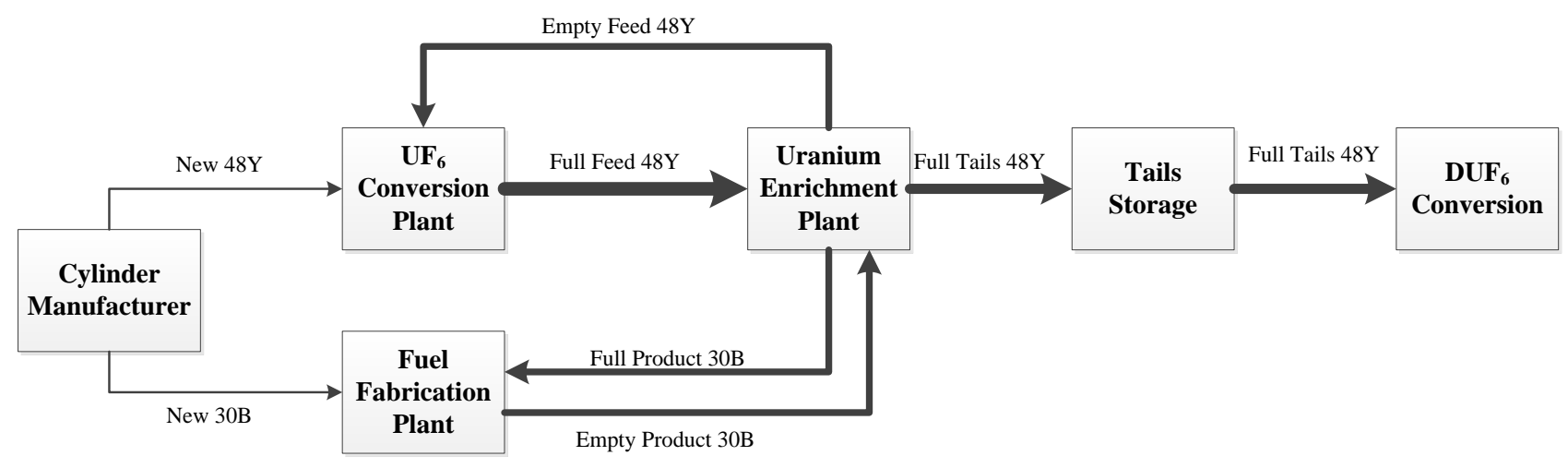

Fig. 1. Movement of 48Y and 30B cylinders within the nuclear fuel cycle.

The team confirmed that cylinders in use today have a variety of markings and identification numbers that are applied by the various companies that handle them. Although the international standards require certain information to be on the cylinder nameplate, the nameplates are often difficult to read and companies generally use their own methods to identify the cylinders (e.g., grease pencil or stickers). While some companies have made an effort to standardize cylinder identification across their facilities (e.g., URENCO's barcode system), there is no widespread use of an automated system for identifying the cylinders. Both the national and international standards that focus on the packing for transport of $\mathrm{UF}_{6}$ require that cylinders not be refilled unless they have been certified within the last 5 years.

A summary of the key cylinder-handling findings is provided below.

- The number of cylinders transported globally between facilities is relatively small and is estimated to be less than 20,000 per year. Additionally, 8,000 model 48Y cylinders are placed in long-term, onsite storage each year.

- Cylinders are exposed to a variety of operating conditions. The most extreme conditions involve withstanding a wide temperature range and exposure to hydrogen fluoride (HF) gas.

- Due to use as pressure vessels, cylinders being filled have to be certified within the previous 5 years.

- National and international standards for cylinder fabrication contain minimum requirements for marking and labeling but do not specify a truly unique numbering format that could be applied industry wide.

- The identification information on the $\mathrm{UF}_{6}$ cylinder nameplate is often difficult to read.

- Many companies apply a variety of additional markings and identification numbers to the cylinders for their on-site material accounting and control purposes (because the nameplates are difficult to read). These multiple markings and labels on individual cylinders can create confusion in determining the actual identification number used on various site and state reports and in reconciling cylinder identification information received from multiple sources.

- The analysis of industry practices for processing and handling cylinders at the three types of facilities at the front end of the fuel cycle that use cylinders provided broad parameters within which a UID and reader system would have to work, and also provided insights into how a UID could be attached in a way that would survive a typical cylinder life cycle. 


\subsection{NONPROLIFERATION}

In examining potential cylinder diversion scenarios and undeclared production pathways, the team evaluated the diversion or misuse of an entire cylinder. Both $30 \mathrm{~B}$ and $48 \mathrm{Y}$ cylinders can contain $\sim 50 \mathrm{~kg}$ of ${ }^{235} \mathrm{U}$, which is equivalent to two SQs of HEU. ${ }^{6}$ Nine scenarios were identified, documented, and evaluated. These pathways are categorized into three primary areas (Table 1):

- the diversion of an entire declared cylinder from a safeguarded facility to a clandestine facility,

- the misuse of a declared cylinder at a safeguarded facility, and

- the introduction of undeclared material into a safeguarded facility (via an undeclared cylinder).

Table 1. Diversion and undeclared production pathways

\begin{tabular}{|c|c|c|}
\hline $\begin{array}{c}\text { The diversion of an entire } \\
\text { declared cylinder to a } \\
\text { clandestine facility }\end{array}$ & $\begin{array}{c}\text { The misuse of a declared } \\
\text { cylinder at a safeguarded } \\
\text { facility }\end{array}$ & $\begin{array}{c}\text { The use of an undeclared } \\
\text { cylinder at a safeguarded } \\
\text { facility }\end{array}$ \\
\hline $\begin{array}{l}\text { Diversion of a declared cylinder } \\
\text { from a facility (conversion, } \\
\text { enrichment, or fuel fabrication) } \\
\qquad-\quad 48 \mathrm{Y} \text { with natural } \mathrm{UF}_{6} \\
\quad-30 \mathrm{~B} \text { with low-enriched } \mathrm{UF}_{6}\end{array}$ & $\begin{array}{l}\text { Feeding a declared cylinder } \\
\text { containing an unexpected } \\
\text { enrichment at an enrichment } \\
\text { facility }\end{array}$ & $\begin{array}{l}\text { The presence of an undeclared } \\
\text { cylinder in a feed/withdrawal } \\
\text { station }\end{array}$ \\
\hline \multirow[t]{2}{*}{$\begin{array}{l}\text { Diversion of a declared cylinder } \\
\text { during shipment between facilities } \\
\text { (e.g., staged theft or loss) } \\
\text { - Between conversion and } \\
\text { enrichment } \\
\text { - Between enrichment and } \\
\text { fuel fabrication }\end{array}$} & $\begin{array}{l}\text { Misuse of declared cylinder } \\
\text { _ Transferring the } \mathrm{UF}_{6} \text { from a } \\
\text { declared cylinder to an } \\
\text { undeclared cylinder } \\
\text { - Using a declared "empty" } \\
\text { cylinder filled with } \\
\text { undeclared material }\end{array}$ & $\begin{array}{l}\text { The presence of an undeclared } \\
30 \mathrm{~B} \text { or } 48 \mathrm{Y} \text { cylinder on-site }\end{array}$ \\
\hline & $\begin{array}{l}\text { Reuse of a cylinder slated for } \\
\text { decommission/destruction with } \\
\text { undeclared material }\end{array}$ & $\begin{array}{l}\text { Applying duplicate nameplates to } \\
\text { an undeclared cylinder }\end{array}$ \\
\hline
\end{tabular}

The IAEA goal for detecting the diversion of a SQ of natural and low-enriched uranium is 1 year. The team evaluated the capability of the current international safeguards regime to detect the diversion and undeclared production pathways (Table 1) and compiled the following key observations.

- $\quad$ Each $48 \mathrm{Y}$ and $30 \mathrm{~B}$ cylinder can contain enough ${ }^{235} \mathrm{U}$ to produce two SQs of HEU.

- Even a modestly sized clandestine enrichment facility (10,000-25,000 SWU/year) operating with natural uranium as its feed material could be capable of producing a SQ of HEU in less than 1 year (i.e., less than the IAEA goal for detecting the cylinder's disappearance). If a full 30B cylinder containing LEU in the $3.5-5 \%{ }^{235} \mathrm{U}$ range were fed, this same plant could produce an SQ of HEU in a considerably shorter time period.

- A proliferant state diverting material may not be (and likely will not be) intending to defeat safeguards for an extended period of time. The state may only need enough time to produce the desired quantity of HEU desired before the activity is detected. ${ }^{3}$ 
- There are diversion scenarios that can use existing safeguarded enrichment facilities to produce HEU in ways that may not be detected by the currently implemented safeguards measures, particularly not within the 1-year detection goal. In most of the scenarios that the team identified and evaluated, a proliferator could divert a full cylinder of material with little chance of being detected.

- A proliferant state, possibly in collusion with another state, could declare cylinders to be lost or stolen in order to conceal their diversion. ${ }^{3}$ While any shipped cylinder that does not arrive as its destination will eventually be identified by the IAEA transit matching process, more than 3 months can elapse before the IAEA identifies the discrepancy. IAEA transit matching is far from a foolproof system. In some cases this matching process can take up to a year before the IAEA can confirm both shipment and receipt of nuclear material.

- Scenarios involving excess production attempt to disguise a period of unrecorded throughput. Current IAEA safeguards do not specifically address these scenarios. For four cases evaluated during the Task 1 studies, the diversion of a full cylinder of material may never be detected by the IAEA. ${ }^{4}$

- If a cylinder is simply diverted from a storage yard, the IAEA likely would not detect its absence until the next physical inventory verification — up to 14 months later.

- Given that there is no unique tamper-indicating cylinder identification tag, an inspector currently does not have a systematic way to detect certain concealment activities such as nameplate swapping.

- The IAEA does not monitor empty cylinders, which could be utilized in a diversion or undeclared production scenario. The team concluded that such cylinders should be accounted for in some manner to detect such use.

\section{SUMMARY AND RECOMMENDATIONS FOR A CYLINDER IDENTIFICATION AND MONITORING SYSTEM}

Based on the Task 1 analysis, the IAEA 1 -year timeliness goal to detect the diversion of a $\mathrm{UF}_{6}$ cylinder is too long; even a small enrichment facility (10,000-25,000 SWU) operating with natural uranium as its feed is capable of producing a SQ of HEU in less than 1 year. If this small enrichment facility began with LEU from a diverted 30B cylinder, the time to HEU could be as short as 30 days. ${ }^{4}$

The current IAEA safeguards measures (1) cannot effectively detect all the credible scenarios for diverting an entire $\mathrm{UF}_{6}$ cylinder before its contents can be converted into HEU, (2) have limited capabilities for detecting undeclared production pathways using natural feed, (3) have limited capabilities for recognizing undeclared cylinders in a country, and (4) do not provide for generating a complete inventory of all cylinders in a country (including empty cylinders). The latter information might be of value in the context of state-level analysis to verify that there are no undeclared nuclear activities and materials in a state. Additionally, the time frames associated with reconciliation of cylinder transfers between a nuclear weapons state and a non-nuclear weapons state (i.e., IAEA transit matching) can exceed the HEU SQ production time frame. ${ }^{3,4}$

The team compiled the following key recommendations for use in developing requirements for the global cylinder identification and monitoring system.

- The UID must be designed to function in all the operating conditions including a wide temperature range and exposure to HF gas and have a minimum life expectancy of 10 years (currently many cylinders remain in circulation $30-40$ years). 
- The UID must be tamper indicating, authenticating, and have the capability to be automatically scanned or read in some fashion. This will eliminate the potential for transposition errors and provide for the development of unattended monitoring systems.

- For new cylinders, it is desired that that the UID be installed during fabrication. Until the fabrication standards are revised, UIDs for new 48Ys could be applied at conversion plants, and UIDs for 30Bs could be applied at enrichment plants.

- For existing cylinders currently in active circulation, the UID could be applied either during the recertification process or when they are routed back through conversion or enrichment plants to be refilled.

- The time required to receive confirmation that a shipped cylinder has arrived at its destination should be shortened to the time required to convert its contents to HEU (i.e., thirty days for a LEU cylinder and 90 days for a natural uranium cylinder).

- Cylinders containing more than an SQ that are placed in static storage should be randomly checked more frequently than once a year during the annual physical inventory.

- A complete "registry" of all $\mathrm{UF}_{6}$ cylinders, coupled with a capability to read the UID on "registered" cylinders at carefully selected nodes in a safeguarded facility, could significantly increase the capability of quickly recognizing the presence of any unregistered cylinders. A registry of cylinders would also improve the capability of IAEA to match transfers between countries.

- Additional safeguards measures for continuously monitoring throughput at conversion and enrichment facilities are needed to address the undeclared production scenarios. A cylinder identification and monitoring system could be a key enabler of a robust safeguards approach that incorporates such additional measures.

- Should a cylinder be diverted from a site or during transport, some form of cylinder monitoring or surveillance would prove valuable by establishing the last known location of the cylinder.

- Cylinder monitoring would also prove valuable in detecting scenarios involving content swapping or nameplate switching.

- Monitoring of empty cylinders would prove valuable in detecting scenarios involving feeding undeclared material.

\section{REFERENCES}

1. B. Boyer et al., "Next Generation Safeguards Initiative: Overview and Policy Context of $\mathrm{UF}_{6}$ Cylinder Tracking Program," July 2012, INMM Annual Meeting, Orlando, FL.

2. J. L. White-Horton et al., The Life Cycle of $30 B$ and $48 Y$ Cylinders, ORNL/TM-2011/522, April 2011.

3. S. Branney et al., Identifying $U F_{6}$ Cylinder Diversion and Undeclared Production Pathways, SRNL, January 2012.

4. M. Curtis et al., Methods of Detecting Diversion and Undeclared Use of UF ${ }_{6}$ Cylinders, PNNL-22017, November 2012.

5. C. Scherer and B. Boyer, Developing an International Standard for Identifying Uranium Hexafluoride Cylinders, LA-UR-12-01286, LANL, February 2012.

6. G. Eccleston et al., Monitoring Uranium Hexafluoride (UF $\left.{ }_{6}\right)$ Cylinders, ORNL/TM-2009/128, June 2009, p. vii. 